\title{
The seasonal dynamics of a High Arctic plant-visitor network: temporal observations and responses to delayed snow melt ${ }^{1}$
}

\author{
Mark A.K. Gillespie and Elisabeth J. Cooper
}

\begin{abstract}
Plant-visitor food webs provide important insights into species interactions, and more information about their seasonal dynamics is vital to understanding the resilience of species to external pressures. Studies of Arctic networks can also improve our understanding of species responses to the pressures of climate change. This study provides the first description of a plant - insect visitor network in Svalbard, a High Arctic archipelago already experiencing the consequences of climate change. A subset of the network was collected from experimental plots where the snow melt date was delayed with snow fences. The deep snow plots delayed flowering and we expected this to disrupt plant-visitor interactions compared with ambient snow conditions. However, the composition of flowers and insect visitors were similar between regimes, and the network tracked patterns of overall flowering phenology. Nevertheless, the deep snow significantly reduced the average overlap between flower availability and insect activity, reducing the probability of an interaction. We suggest that at a landscape scale, Arctic pollinators will benefit from patchy changes to snow melt that maintain heterogeneity in the timing of flowering but changes that increase homogeneity in snowmelt across the landscape may negatively impact some species.

Key words: climate change, flowering plants, insect pollinators, interaction network, snow fences.

Résumé : Les réseaux alimentaires plantes-visiteurs fournissent des informations importantes sur les interactions entre les espèces, et il est essentiel de disposer de plus d'informations sur leur dynamique saisonnière pour comprendre la résilience des espèces aux pressions externes. Les études des réseaux arctiques peuvent également améliorer notre compréhension des réponses des espèces aux pressions provoquées par les changements climatiques. Cette étude fournit la première description d'un réseau de visiteurs plantes-insectes au Svalbard, un archipel du Haut-Arctique qui subit déjà les conséquences des changements climatiques. Un sous-ensemble du réseau a été collecté sur des parcelles expérimentales où la date de fonte des neiges a été retardée par des barrières de neige. Les parcelles de neige profonde retardaient la floraison et les auteurs s'attendaient à ce que cela perturbe les interactions plantes-visiteurs par rapport aux conditions de neige ambiante. Toutefois, la composition en fleurs et en insectes visiteurs était similaire entre les
\end{abstract}

Received 13 November 2020. Accepted 7 June 2021.

M.A.K. Gillespie. Department of Arctic and Marine Biology, Faculty of Biosciences, Fisheries and Economics, UiT - The Arctic University of Norway, 9037 Troms $\emptyset$, Norway; Department of Environmental Sciences, Western Norway University of Applied Sciences, Sogndal Campus, PB 133, 6851 Sogndal, Norway.

E.J. Cooper. Department of Arctic and Marine Biology, Faculty of Biosciences, Fisheries and Economics, UiT — The Arctic University of Norway, 9037 Troms $\emptyset$, Norway.

Corresponding author: Mark Gillespie (email: markg@hvl.no).

${ }^{1}$ This paper is part of a Special Issue entitled: Impacts of climate change on tundra ecosystems: Three decades of results from the International Tundra Experiment (ITEX).

() 2021 The Author(s). This work is licensed under a Creative Commons Attribution 4.0 International License (CC BY 4.0) http://creativecommons.org/licenses/by/4.0/, which permits unrestricted use, distribution, and reproduction in any medium, provided the original author(s) and source are credited.

A correction was made to the e-First version of this paper on 18 January 2022 prior to the final issue publication. The current online version contains the correction. 
régimes, et le réseau suivait les patrons de la phénologie globale de la floraison. Néanmoins, la neige profonde réduisait de manière significative le chevauchement moyen entre la disponibilité des fleurs et l'activité des insectes, réduisant ainsi la probabilité d'une interaction. Les auteurs suggèrent qu'à l'échelle du paysage, les pollinisateurs de l'Arctique bénéficieront de changements parcellaires de la fonte des neiges qui maintiennent l'hétérogénéité de la période de floraison, mais que les changements qui augmentent l'homogénéité de la fonte des neiges dans le paysage peuvent avoir un impact négatif sur certaines espèces. [Traduit par la Rédaction]

Mots-clés : changement climatique, plantes à fleurs, insectes pollinisateurs, réseau d'interaction, barrières de neige.

\section{Introduction}

Recent work in pollination ecology has explored the temporal dynamics of plantvisitation networks for within- and between-season patterns, to understand how such important webs are structured and built up through time (Pradal et al. 2009; Rasmussen et al. 2013; Caradonna et al. 2017). Such an understanding can help predict the resilience of these food webs to environmental disturbances (Encinas-Viso et al. 2012; Caradonna et al. 2017). Certain key properties of these networks, such as species number for each trophic level and the number of links between species and network connectance, have been found to vary across time (Lundgren and Olesen 2005; Olesen et al. 2008; Petanidou et al. 2008; Burkle et al. 2013), and network structure has a strong temporal dimension (Nielsen and Bascompte 2007; Olesen et al. 2008; Rasmussen et al. 2013; Valverde et al. 2016). Hence, many authors have encouraged further consideration of the temporal dimension to these networks (Burkle and Alarcón 2011; Bascompte and Jordano 2014; Poisot et al. 2015). In particular, there is a strong need to demonstrate network dynamics at latitudes and altitudes where seasonality and environmental change is a key driver of species phenology and interactions (Høye and Forchhammer 2008; Pradal et al. 2009; Schmidt et al. 2016).

Plant-visitation networks are constructed by quantifying the mutualistic interactions between flowering plant species and flower-visiting insect species, often assuming that the latter are performing a pollination role (Bascompte and Jordano 2007). The properties of such networks can tell us much about the mechanisms behind network assembly and stability, and tend to be conserved across a range of biomes (Bascompte et al. 2003). However, much less is known about whether general network properties of "static" networks (those constructed using data from the entire season) can be generalised to "dynamic" networks, or those representing a range of different time points (Caradonna et al. 2017). For Arctic regions, most of the work on plant-visitation networks has come from Greenland, where network properties were found to be stable between years, but within-season dynamics revealed more ecologically relevant information (Olesen et al. 2008). For example, the first insect species to join the network (i.e., to interact with a flowering plant) tend to be those with the longest active flying period and the highest abundances, and therefore are more likely to visit a wide range of plant species within the network (Olesen et al. 2008; Rasmussen et al. 2013), compared with less common species with shorter periods of interaction with flowers (Rasmussen et al. 2013). These fundamental properties are important to document for a range of systems to improve our understanding of network assembly and resilience to external pressures (Caradonna et al. 2017). For example, in snow-covered regions, the start of the growing season is typically defined by snow melt regimes and air temperatures, and these can affect plants and flower visitors differently (Kudo and Cooper 2019).

In Svalbard, a High Arctic archipelago already experiencing the effects of climate change, little is known about the dynamics of plant-visitor interactions. Therefore, the 
main objective of this study was to construct the first plant-visitor network for Svalbard and compare the characteristics with networks recorded for other Arctic locations. The Svalbard fauna has only 15 insect species considered important for pollination, compared with 71 in North East Greenland (Gillespie et al. 2020). Svalbard also has only 184 vascular plant species (Alsos et al. 2020), a fairly low number in relation to comparative neighbouring Arctic areas (375 species in Canada (Gillespie et al. 2015) and 532 in Greenland (Bay 2020)), and influx of new species is restricted due to its remoteness from other land masses. With such limited species richness of both trophic levels, the network is likely to be simpler than in other High Arctic locations (Lundgren and Olesen 2005; Burkle and Alarcón 2011; Robinson et al. 2018). However, as network generalisation increases with latitude and is lower for islands (Olesen and Jordano 2002), Svalbard provides an interesting trade-off location as an isolated, high-latitude archipelago. We hypothesised (H1) that Svalbard would have a species-poor network, commensurate with the archipelago's low insect biodiversity. We also hypothesised (H2) to find similar temporal dynamics to other High Arctic networks, in that the network would exhibit a gradual build-up and sudden collapse. The latter characteristic occurs because the flowering season comes to an abrupt halt due to either the limited length of flowering for many species that have periodic phenology (Semenchuk et al. 2016), or the onset of cold autumn weather and significant reduction in day length (e.g., Pradal et al. 2009).

The current warming climate in the Arctic and other snow-covered areas plays a crucial role in plant-pollinator interactions, with phenological changes likely to affect the coupling between some plants and pollinators (Rasmussen et al. 2013; Schmidt et al. 2016; Kudo and Cooper 2019). This prediction has not been explored in detail in the High Arctic as studies rarely cover the timespan required to establish connections between network dynamics and abiotic factors or experimentally explore the impacts of climate drivers (Burkle and Alarcón 2011). Here, we adopt the latter approach using an experiment that artificially delays snow melt at the plot level leading to delayed flowering (Semenchuk et al. 2016). We previously showed that peak insect visits tended to move from flowers in ambient conditions to the later emerging flowers in deep snow plots, apparently prolonging the flowering season across the local landscape at the site level (Gillespie et al. 2016). However, here we focus on the static and dynamic network properties and the impact of snow melt delay on the likelihood of flowers and insects interacting. To date, only one other study has explored the impact of experimentally altered snow melt on plant-visitor networks and found that advanced snow melt increased the degree of specialisation due to shifts in flower phenology (Hoiss et al. 2015). Advanced flowering may have reduced the availability of resources for insect visitors by creating temporal mismatches (Memmott et al. 2007). As our delayed snow melt regime also only manipulates one half of the interaction, we similarly hypothesised (H3) that delays to flowering phenology would result in reduced floral resource availability for insects. The findings from this experiment provides important insights into the response and resilience of interacting species in snow-covered landscapes to changes in the phenology of resource availability.

\section{Methods}

\section{Study site and experimental design}

The study was carried out in 2015 in Adventdalen $\left(78^{\circ} 10^{\prime} \mathrm{N}, 16^{\circ} 06^{\prime} \mathrm{E}\right)$ on Svalbard, in an area approximately $2.5 \mathrm{~km} \times 1.5 \mathrm{~km}$, with mean July temperature of $5.9^{\circ} \mathrm{C}$ and $190 \mathrm{~mm}$ annual precipitation, most of which falls as snow and is subsequently redistributed by strong winds. We focused on two common vegetation types: mesic meadow (dominant species: Dryas octopetala L., Alopecurus ovatus Knapp., Luzula confusa Lindeb., Salix polaris Wahlenb., Bistorta vivipara (L.) Delarbre, and bryophytes) and a drier heath (dominant 
species: Cassiope tetragona (L.) D. Don, D. octopetala, Salix polaris, and bryophytes). The entire study area was used for collecting data to construct an overall plant-visitor network for Adventdalen.

In order to build separate networks to compare the effects of snowmelt timing, we used fences to experimentally enhance snow depth by $1 \mathrm{~m}$, resulting in approximately 2 weeks of delay in melt ("Deep" snow regime: snowmelt 11 June 2015), paired with adjacent ambient areas (approximately $30 \mathrm{~cm}$ snow depth, snowmelt 26 May 2015, “Ambient" regime). The site, climate, and experimental set-up has been described in detail elsewhere (Morgner et al. 2010; Cooper et al. 2011; Semenchuk et al. 2013), and more details are available in the Supplementary Material ${ }^{2}$. For this part of the study, we used five fence - ambient area pairs in the mesic meadow (Supplementary Table S $1^{2}$ ). At each fence location, permanent vegetation plots $(0.75 \mathrm{~m} \times 0.75 \mathrm{~m})$ were used (two in each of the Deep and Ambient regimes, totaling 20 plots) to record flowering phenology and insect visitation (see below).

\section{Insect sampling}

Flower-visiting insect sampling was undertaken in the summer of 2015 and has mostly been described elsewhere (Gillespie et al. 2016). We give a brief overview here together with details not included in that paper. A full description can be found in the Supplementary Material $^{2}$. Between 17 June and 6 September 2015, there were 22 suitable days for sampling flower visitors. Each day, flowers were observed in the 20 permanent plots for 10 -minute intervals and whenever an insect landed on a flower it was caught and the plant species was noted. The plots of the study site varied in flower density and species composition, with some consisting of large flowers (e.g., D. octopetala) and others containing only small flowers (e.g., B. vivipara). In many cases, the plots often accommodated a low number of flowering species and few flowers, so insect sampling was supplemented with additional observations outside the marked plots (but within the study area) in order to build-up an overall network of plant-insect interactions. On each day, the study area, including the heath and other Deep areas, was searched for flowering plants of all species not included in the plots. Where possible, two individuals of each additional (non-plot) flowering species were randomly selected and observed for $10 \mathrm{~min}$. This sampling methodology is likely to have led to oversampling of the more common species found in plots (see Supplementary Table $S 2^{2}$ for a list of species and the number of flowers observed on each date). However, we have retained all records in our analysis due to the low number of observations resulting from subsampling. Under the cool Adventdalen conditions, the insects were docile and easy to catch and, therefore, the vast majority of observed individuals were caught. On the rare occasion that individuals were missed, they were noted to a broad taxonomic level; the addition of these data did not affect the results, so they were omitted. We randomised the order of plot sampling each day to avoid possible confounding effects of sampling time. Insects were identified to family level because good identification keys were lacking for many species.

\section{Plant phenology}

In order to compare insect visitation patterns with the flowering duration of different plants, the phenology of flowering stages was estimated from plot level counts of the six most abundant flowering plant species in the study plots (B. vivipara, Cassiope tetragona, D. octopetala, Stellaria longipes subsp. longipes Goldie, Salix polaris, and Cerastium arcticum Lange). See Gillespie et al. (2016) for details of the first four of these species, but briefly, the number of flowers were counted in each plot every 3-4 days for the entire flowering

\footnotetext{
${ }^{2}$ Supplementary data are available with the article at https://doi.org/10.1139/as-2020-0056.
} 
season in 2015. For Salix polaris and Cerastium arcticum, plot level flower counts were made during insect surveys (every 2-8 days; see above). Flowering duration for all other flowering species included in this study was estimated from insect visitation records. In all cases, the date of first flowering was taken as the day of the year when the first flower emerged at the entire site, and the end of flowering was defined as the day of the year when the last open flower was recorded.

\section{Data analysis}

All data analyses were conducted using the R programming environment (version 3.6.2, $R$ Core Team 2019). The data from all plant-insect observations were first pooled in order to construct a full-season static plant-visitor network for the Adventdalen study community. To increase the size of the data set, this included plant-insect visitation observations from Deep areas, which we assume represent the snow depth and melt of gulley areas in Adventdalen, as recent work has shown similarity in snowmelt timing of our Deep regime and nearby gullies (Moriana-Armendariz et al. in press). Network diagrams were produced using the bipartite package (Dormann et al. 2008). The structure of the network was compared with four other Arctic networks published previously (see Supplementary Material ${ }^{2}$ for details). To study the seasonal build-up of the network, we separated the data into temporal windows or "time slices". To avoid arbitrarily determining the time slices and ensure that each one was populated with sufficient data ( $>2$ days and $>30$ interactions), we used a method described by Valverde et al. (2016; see Supplementary Material ${ }^{2}$ for details). This resulted in pooling of the surveys into seven temporal windows of 8 days length and each window contained 2 or 3 survey days.

We compared the networks in experimental plots in two ways. First, we compared the data from Ambient against Deep to identify any differences in overall network structure and the appearance of phenological mismatches due to a delay in snow melt. This comparison was largely descriptive as plot level data were not sufficient to conduct statistical modelling. Nevertheless, to explore whether the resulting pattern was different between the experimental regimes, we fit general additive models (GAM) with the mgcv package (Wood 2017) with the quasi-poisson family to account for overdispersion in the response variables: the number of species and number of links. For both models, snow regime was a fixed effect, and day of the year (DOY; the day of the year of the survey as a number, where 1 January = day 1) was fit with a penalised thin plate regression spline smoother (bs = "ts"). To test whether the smoother differed between snow regimes, we treated the categorical variable as ordered, with Ambient as the reference level, and fit a "difference" smooth as a factor-smooth interaction using the by argument. In both cases, the models were checked for normality and homogeneity of variance in the residuals. After fitting the model, we used posterior inference with 10000 simulations to calculate the maximum point on each curve and estimate the DOY (and 95\% confidence intervals) when the networks reached peak number of links or species.

Finally, we examined the indirect effect of the snow regime on plant-visitor interactions via the overlap between plant and insect phenophases (H3). As a greater degree of overlap between insect visitors and plants is more likely to lead to an interaction (Olesen et al. 2011), we tested whether delayed flowering led to reduced overlap in phenophases and subsequently a reduced likelihood of visitation. Here, the term phenophase refers to the period of flowering for plants, and the period of active flying for adult insects. In this part of the study, the phenophases were calculated using insect visitation data only. Therefore, flower onset and senescence dates were defined by the first and last dates a flower was observed in any plot, regardless of whether it was visited by an insect. Similarly, insect start and end dates were recorded as the date an insect was first or last caught. 
To test H3, we used a "piecewise" path model, a method of piecing together the coefficients of several "submodels", which can be built using a range of mixed model techniques (Lefcheck 2016). We constructed two submodels for the hypothesised path model. The first was a zero-inflated generalised linear mixed model (GLMM) with poisson-distributed errors. The length of overlapping periods between the phenophases of all plant-visitor species pairs found within the plots (sensu Olesen et al. 2011), hereinafter termed "overlap", was the response variable, and snow regime was the explanatory variable. To account for differences in plant species availability and insect abundance, we included plant species and insect family as random factors. The zero-inflated part of the submodel included the same structure to predict excess zeros. The second submodel was a GLMM with binomial distributed errors, using the binary link variable as response $(1=$ an insect family visited the plant species, $0=$ absence of a link), snow regime and overlap as explanatory variables, and the same random factors as above. Both models were fit using the glmmTMB package (Brooks et al. 2017) and were assessed for normality and homogeneity of residuals and overdispersion using the DHARMa package (Hartig 2020). Usually, after fitting valid submodels, piecewise path models are assessed for goodness of fit using Shipley's test of directed separation (Shipley 2000; Lefcheck 2016), whereby "missing paths" are tested using the Fisher's C test statistic. However, as our path model represents a saturated model, there are no missing paths to test and the resulting regression coefficients can be used to infer the significance and magnitude of paths in the model.

\section{Results}

Static full season network

Over the 22 days of sampling from 17 June to 21 August 2015, 19 plant species were observed receiving insect visitors (two species, Ranunculus nivalis L. and Micranthes nivalis (L.) Small, were observed but did not receive visitors) and 11 insect families were determined with a total of 685 insect specimens collected. The "static" plant-visitor network of Adventdalen using data collected over the entire field season and sampling site is depicted by a bipartite network matrix (Fig. 1). The network shows that 8 of the 19 plants were more generalist in that they received visits from a range (5-6) of insect families. These plant species received over $68 \%$ of the visits by insects. The most visited plant species was $D$. octopetala (191 visits), followed by Salix polaris (157 visits) and Stellaria longipes subsp. longipes (93 visits). However, it should be noted that the number of flowers observed were not equally divided among the plant species (Supplementary Table S2 ${ }^{2}$ ). It is therefore likely that the number of visits to plants within permanent plots are overestimated compared with less common plants.

Of all the insect specimens collected, 79.4\% were Diptera (true flies), with the Sciaridae, Chironomidae, Empididae, and Muscidae responsible for the majority of interactions (Table 1). The remaining $20.6 \%$ of interactions were by Hymenoptera (wasps), with the vast majority $(20.3 \%)$ being ichneumonid wasps. Most insect families had links to several plant species, although Fig. 1 depicts some key associations in the network, with a high number of visits (63) on D. octopetala by Empididae and on Stellaria longipes subsp. longipes by Ichneumonidae (72), for example.

As with networks described elsewhere in the Arctic (Table 2), the Adventdalen network is small relative to those in temperate regions. The system size and number of interactions are most similar to the networks described at a similar latitude at Alexandra Fjord, Canada, and the island of Uummannaq, Greenland, although those networks were established over much smaller spatial scales. Connectance indicates the level of generalisation in the network, with high percentages associated with a high number of generalist species, and this is quite similar across most Arctic networks. However, those with a higher level of 
Fig. 1. Plant-visitor matrix for Adventdalen, Svalbard, based on log number of visits during summer 2015. Flowering plant species are listed as rows and insect families as columns. A shaded square indicates the presence of a link and the darkness of the shading is related to the log number of visits. The matrix is sorted in a nested fashion in that plant species are sorted downward according to descending number of links (number of insect species that visited the plant), and insect species are sorted from left to right according to descending number of links. Thus, the upper left corner of the matrix is made up of links between plant and insect generalists.

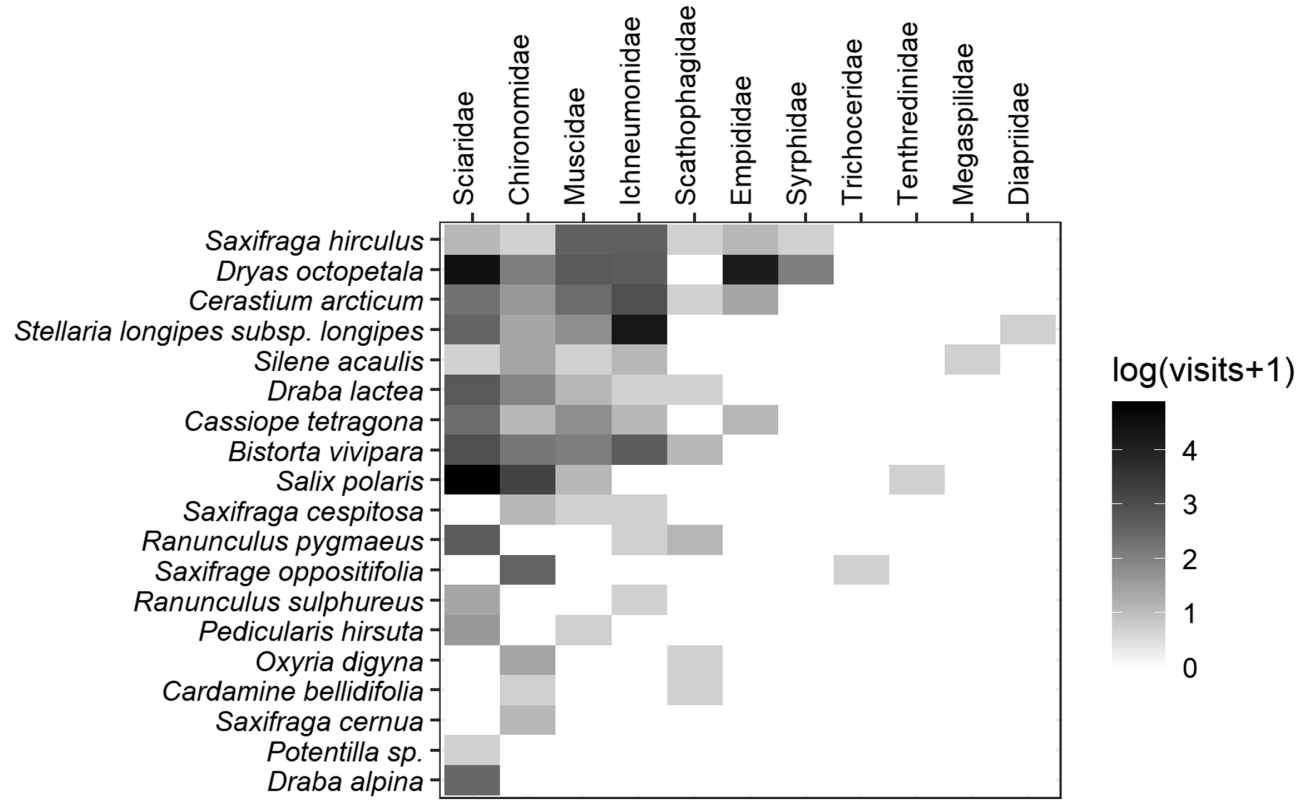

Table 1. The number of insect specimens and plant species visited for each family of insect captured visiting flowers at the Adventdalen study site.

\begin{tabular}{lllll}
\hline Insect order & Insect family & $\begin{array}{l}\text { No. of possible } \\
\text { species }\end{array}$ & $\begin{array}{l}\text { No. of } \\
\text { specimens, } n \text { (\%) }\end{array}$ & $\begin{array}{l}\text { No. of plant } \\
\text { species visited }\end{array}$ \\
\hline Diptera & Chironomidae & 126 & $78(11.4)$ & 14 \\
& Empididae & 1 & $69(10.1)$ & 4 \\
& Muscidae & 8 & $62(9.1)$ & 11 \\
& Scathophagidae & 4 & $9(1.3)$ & 7 \\
& Sciaridae & 13 & $316(46.1)$ & 14 \\
& Syrphidae & 3 & $8(1.2)$ & 2 \\
& Trichoceridae & 5 & $1(0.14)$ & 1 \\
& Tenthredinidae & 10 & $1(0.14)$ & 1 \\
& Ichneumonidae & 22 & $139(20.3)$ & 11 \\
& Diapriidae & 1 & $1(0.15)$ & 1 \\
& Megaspillidae & 1 & $1(0.15)$ & 1 \\
& Total & 194 & 685 & 19 \\
\hline
\end{tabular}

Note: The number of species that are currently known to occur on Svalbard for each family is also given.

taxonomic resolution have much lower connectance values, so the true value for Adventdalen is likely to be lower. The mean interactions per insect or plant species (linkage level) are also indicators of generalisation at each trophic level, and the estimate for plants in Adventdalen is low at 3.9, and similar to the Uummannaq study. 
Table 2. Summary information of the Adventdalen plant-visitor network compared with other high-latitude networks.

\begin{tabular}{|c|c|c|c|c|c|c|c|c|}
\hline & \multicolumn{2}{|c|}{$\begin{array}{l}\text { Abisko, Sweden } \\
\text { (Elberling and } \\
\text { Olesen 1999) }\end{array}$} & \multicolumn{2}{|c|}{$\begin{array}{l}\text { Uummannaq, } \\
\text { Greenland } \\
\text { (Lundgren and } \\
\text { Olesen 2005) }\end{array}$} & \multicolumn{2}{|c|}{$\begin{array}{l}\text { Zackenberg, } \\
\text { Greenland (Olesen } \\
\text { et al. 2008)* }\end{array}$} & \multirow{2}{*}{$\begin{array}{l}\text { Alexandra Fjord, } \\
\text { Canada (Robinson } \\
\text { et al. 2018) } \\
\text { Family } \\
\text { level }\end{array}$} & \multirow{2}{*}{$\begin{array}{l}\text { Adventdalen, } \\
\text { Svalbard } \\
\text { Family } \\
\text { level }\end{array}$} \\
\hline & $\begin{array}{l}\text { Original } \\
\text { data }\end{array}$ & $\begin{array}{l}\text { Family } \\
\text { level }\end{array}$ & $\begin{array}{l}\text { Original } \\
\text { data }\end{array}$ & $\begin{array}{l}\text { Family } \\
\text { level }\end{array}$ & $\begin{array}{l}\text { Original } \\
\text { data }\end{array}$ & $\begin{array}{l}\text { Family } \\
\text { level }\end{array}$ & & \\
\hline Latitude of study site & 68 & 68 & 71 & 71 & 75 & 75 & 78 & 78 \\
\hline Number of insect species/families $(a)$ & 118 & 31 & 26 & 19 & 76 & 28 & 23 & 11 \\
\hline Number of visited flowering plant species $(p)$ & 23 & 23 & 17 & 17 & 31 & 31 & 8 & 19 \\
\hline System size $(M=a \times p)$ & 2714 & 713 & 442 & 323 & 2356 & 868 & 184 & 209 \\
\hline Total number of interactions $(I)$ & 242 & 242 & 63 & 63 & 452 & 452 & 41 & 67 \\
\hline Connectance $(100 \times I / M)$ & $9 \%$ & $34 \%$ & $14 \%$ & $20 \%$ & $19 \%$ & $52 \%$ & $22 \% *$ & $32 \%$ \\
\hline Interactions per insect species/family & 2.1 & 7.8 & 2.4 & 3.3 & 5.9 & 16.1 & 1.8 & 6.1 \\
\hline Number of interactions per plant species & 10.5 & 10.5 & 3.7 & 3.7 & 14.6 & 14.6 & 5.1 & 3.9 \\
\hline
\end{tabular}

Note: Studies with high-level taxonomic resolution for insects have been summarised at the family level for direct comparison. System size ( $M$ ) represents the theoretical maximum size of the network. However, not all links occur in reality, and connectance represents the percentage all interactions that were realised, and higher connectance indicates more generalist links. Similarly, higher mean interactions per insect/plant species indicate greater generalisation. *, based on 2 years of data. 
Fig. 2. The visitation web of the Adventdalen plant-visitor network, using all site-level data, separated by temporal windows of equal length (8 days) and similar sampling effort (2-3 plant-insect visit observation days), during summer 2015. The diagram is a matrix of interactions with insect families represented by columns (names not shown), visited plant species are represented by rows, and a black square indicating the presence of particular interactions during each time window. Insect taxonomic names have been omitted for clarity, but follow the same order as Fig. 1. The matrices are also sorted in a nested fashion in that plant species are sorted downward according to descending number of links over the whole season, and insect species are sorted from left to right according to descending number of links. Thus, the upper left corner of the matrix is made up of links between plant and insect generalists. DOY, day of year (DOY 174, 23 June; DOY 233, 21 August). Note that observations were not conducted on an equal number of flowers for each species in each time period (see Methods for details).

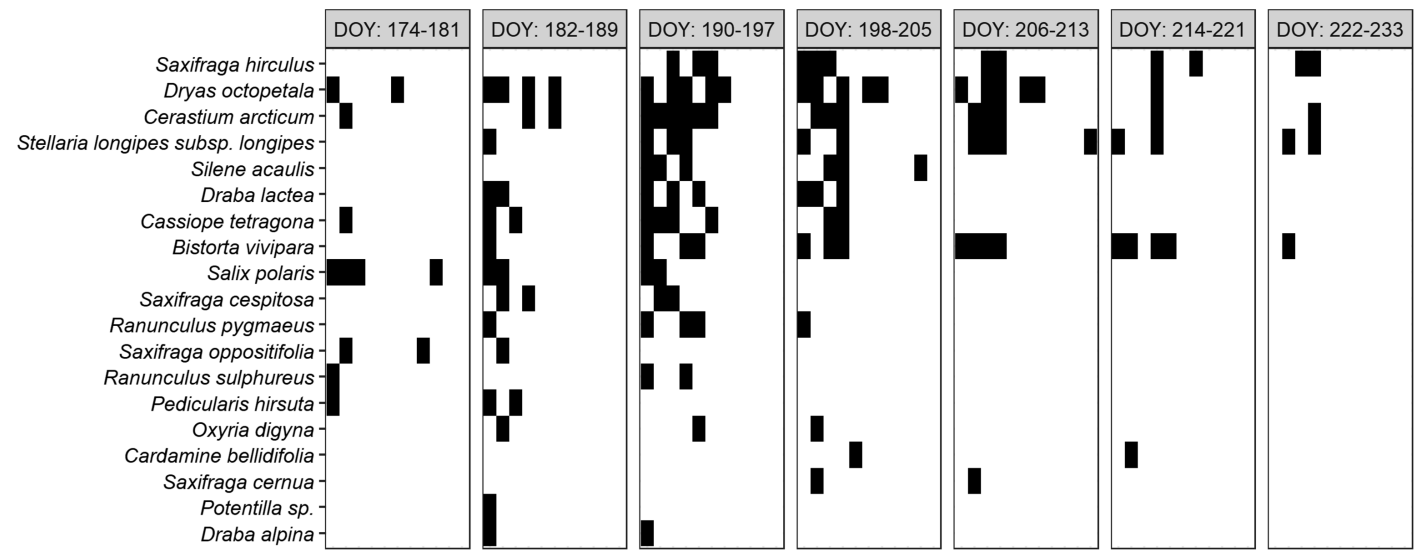

\section{Dynamic temporal network properties}

The plant-visitor interactions observed in each of the seven temporal windows across the entire study site are illustrated using a network matrix diagram (Fig. 2). The presence of different links in the network windows demonstrates the temporal build-up in complexity of the web up to the third temporal window in the second week of July. After this peak, the plant-visitor network gradually decreased in complexity, as more species left the network by senescence (flowers) or inactivity (insects). This structural assembly and disassembly can also be depicted by plotting the number of species and links involved in the network over time (Fig. 3a), showing a hump-shaped relationship to the build-up of both variables. The cumulative number of species and links over the active period (Fig. 3b) displays an almost linear accumulation of both species and links during the peak complexity phase, before slowing down indicating that the period of greatest growth in the network is during 3rd and 4th temporal windows (July).

\section{Snow fence experiment}

Eleven of the 19 plant species sampled in the static network were not present in Deep and were sampled outside of areas manipulated by the snow fences, so observations from these plants have been excluded from the snow fence analysis. Similarly, it is difficult to compare networks built from regimes that are located so close together due to possible spatial nonindependence of observations, so these results should be reviewed with caution.

The plot networks are subsets of the overall network in terms of the number of species involved (Supplementary Table $\mathrm{S}^{2}$ ), and it would be misleading to place emphasis on network parameters. However, the temporal dynamics of these networks do show some indicative signs of the impact of delayed snow melt on network build-up and collapse. The humped shape of species and links over time follows a similar pattern to the overall 
Fig. 3. The pooled number of invertebrate and plant species per survey day, and number of links between pairs of species involved in the overall Adventdalen plant-visitor network plotted against day of year (DOY), using (a) individual survey data and $(b)$ cumulative data, during summer 2015. The curves in the Fig. 3a graph are cubic regression splines.
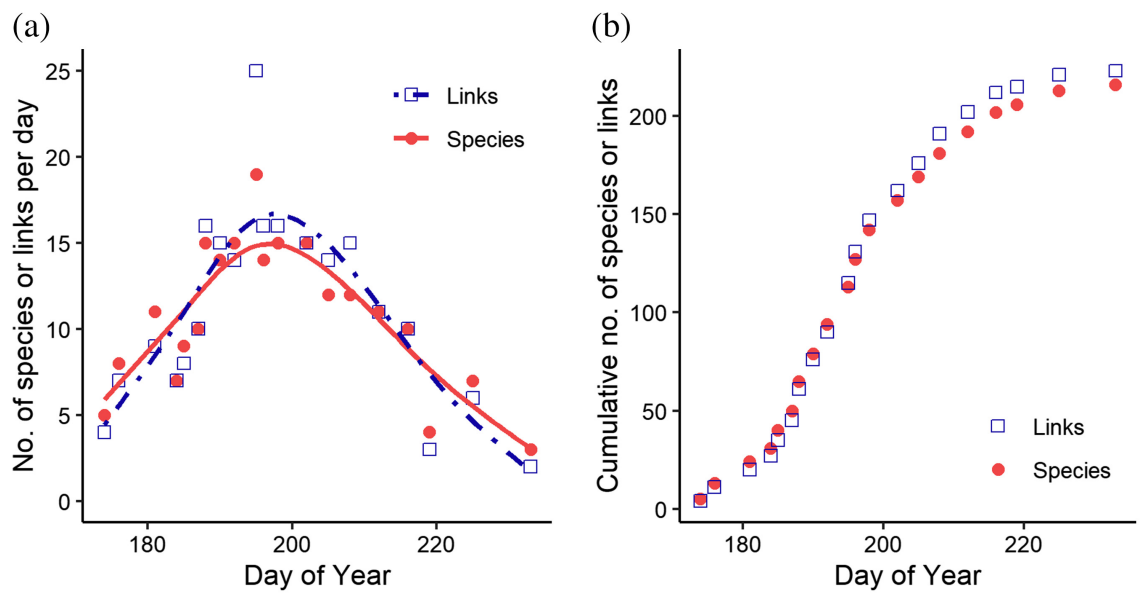

Fig. 4. Number of species for plants and families for insects combined $(a)$ and number of links $(b)$ involved in the plant-visitor networks over the period of flower-insect interactions, with data pooled for each snow fence regime, during summer 2015. The curves are pricted from general additive models with a penalised thin plate regression smoother.

(a)

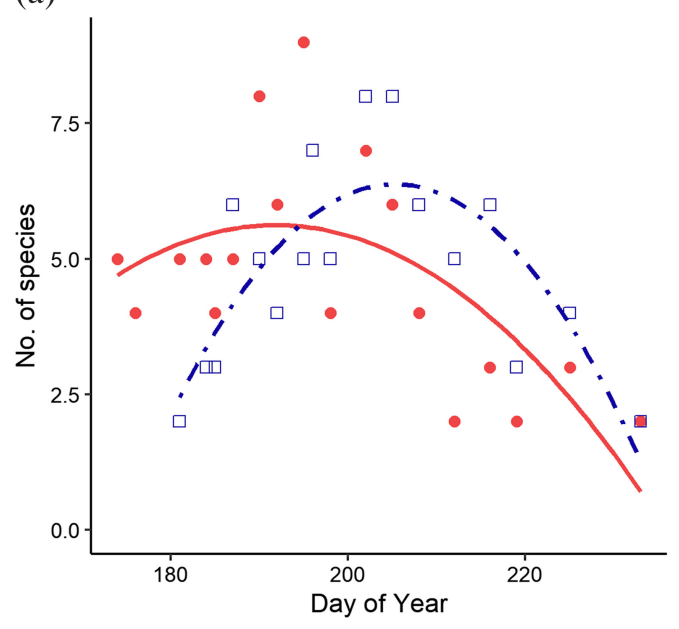

(b)

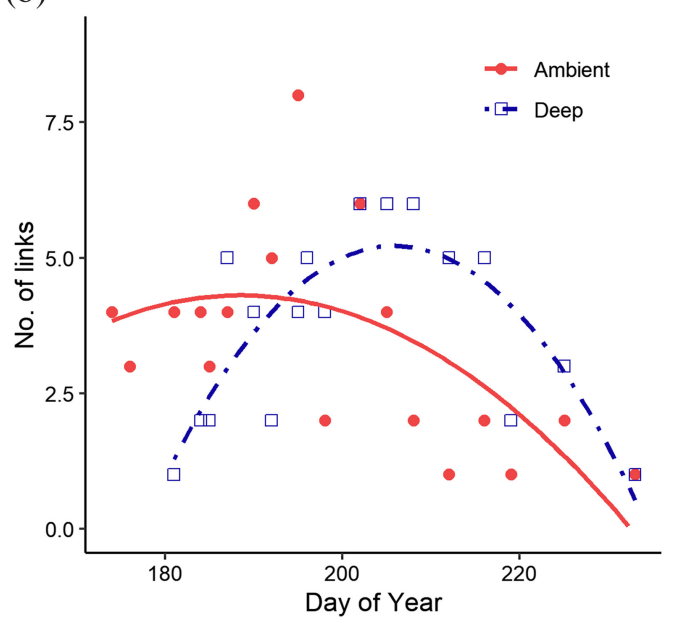

network (Fig. 4). According to the GAM models, the curves for both species and links differed significantly between the snow regimes (species: $F=1.63$, effective degrees of free$\operatorname{dom}=1.83, p=0.001$; links: $F=1.74$, effective degrees of freedom $=1.86, p<0.001$; Supplementary Table $S 4^{2}$ ). This result does not explain where the curves differ significantly, but it is clear that there is a tendency for the curves for Deep species and links to have a delayed start, build-up, peak, and collapse compared with those of Ambient. The peaks of the curves differ by a similar range to the mean delay in snow melt. The peaks of the number of species curves differ by 8.1 days (Ambient peak = day 194.4 (95\% CI = 170.0-200.8), 
Fig. 5. Path model illustrating the indirect impact of snow regime on the probability of observing a link between plants and insect visitors via increasing phenophase overlap between species pairs. Solid arrows indicate a significant relationship at the $p<0.001$ level, dashed arrow indicates a non-significant relationship $(p>0.05)$. Numbers on each arrow are the standardised (and unstandardised) coefficients. Standardised coefficients were calculated using the observation-empirical method. Graphs beneath the paths correspond to the relevant effects: (a) the predicted mean overlap and 95\% confidence intervals for the two snow regimes, and $(b)$ the predicted interaction probability and 95\% confidence intervals from logistic regression for increasing overlap.

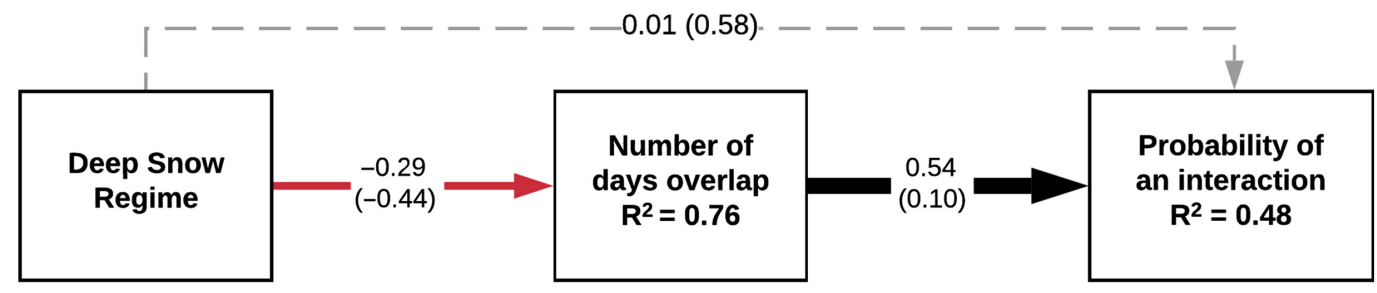

(a)

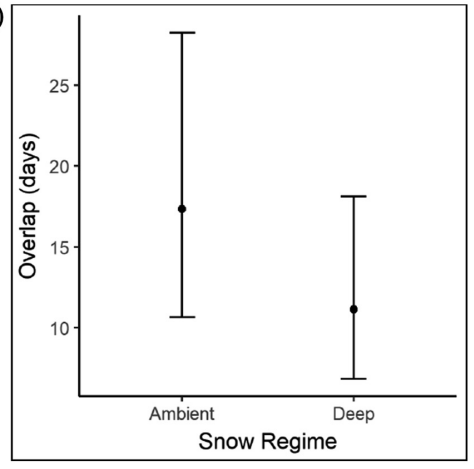

(b)

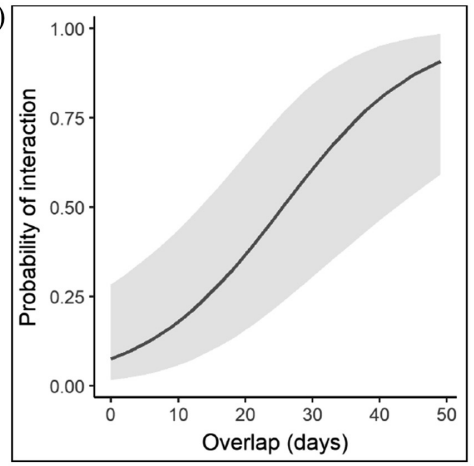

Deep peak = day $202.5(95 \% \mathrm{CI}=197.8-208.7))$ and the peak of the number of links differ by 12.3 days (Ambient peak = day 192 (95\% CI=170.0-199.0), Deep peak=day 204.3 $(95 \% \mathrm{CI}=198.0-212.0))$. It is noteworthy that the two sets of curves end at approximately the same time, indicating a shorter overall active period in Deep compared with Ambient.

The results of the path model (Fig. 5, Supplementary Tables S5 and $\mathrm{S6}^{2}$ ) show a significant impact of snow regime on the overlap between plant flowering and insect activity, with Deep exhibiting on average 6.2 days less overlap (Ambient mean $=17.36 \pm 0.25 \mathrm{SE}$, Deep $=11.13 \pm 0.25 \mathrm{SE} ; z=-8.39, p<0.001$ ). The overlap was subsequently a highly significant positive predictor of interaction probability $(z=3.57, p<0.001)$, but there were no differences in interaction probability between the snow regimes $(z=1.02, p=0.307)$. The path model suggests that deeper snow negatively impacts the average probability of interaction indirectly via the reduction in their overlapping phenologies. The binomial submodel estimates that 25.5 days of overlap are required to reach an interaction probability of 0.5 (95\% CI $=16.5-56.6$ days). As lower levels of overlap were found in Deep (46\% of potential species pairs had an overlap of 5 days or less in Deep, compared with only 33\% in Ambient), enhanced snow with delayed melt is likely to reduce the possibility of reaching high levels of visitation probability.

Phenophase diagrams constructed for the most common flowering plants in the networks for Ambient and Deep also indicate some interesting patterns in network temporal dynamics (Fig. 6). Most of the plant species have flowers that are available for the majority of the flowering season, but they are not utilised for the entire duration of their flowering period, at least using these sampling techniques. Similarly, the main insect families do not continue to visit any of the plants for the entirety of that species' flowering duration, 
Fig. 6. Mean flowers per plot (from biweekly surveys) for the six most abundant flowering species of plants in the meadow habitat (line graphs, Ambient = solid red line, Deep = dashed blue line), and duration of insect visitor activity represented as boxplots. The black line for each insect taxon indicates the entire phenophase recorded from all records at the study site. The coloured boxplots for each taxon indicate the period from the first to the last interaction recorded in either Ambient (red) or Deep (blue) plots. Note, some insects were not recorded for certain plant species in both snow regimes, hence the occasional lack of a blue or red boxplot for that plantinsect species combination.
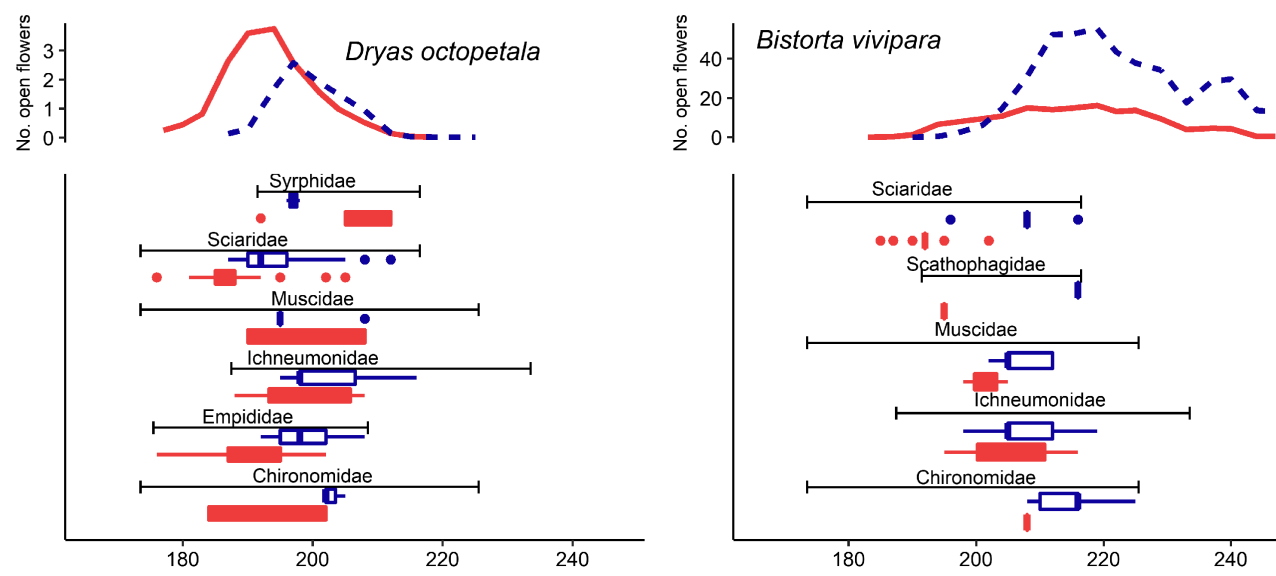

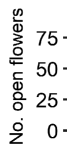
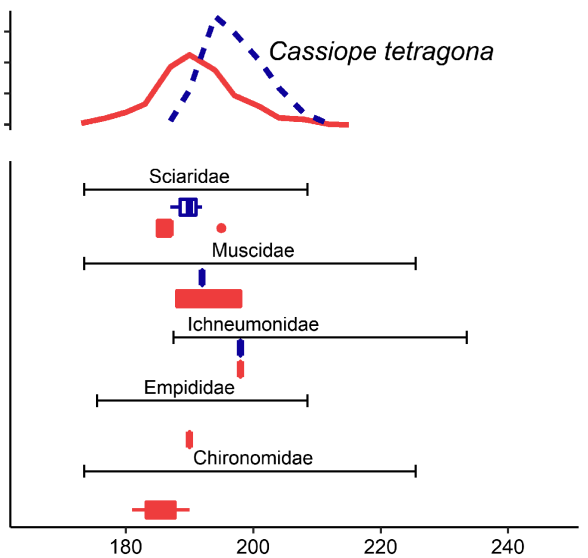

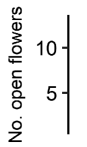

Salix polaris

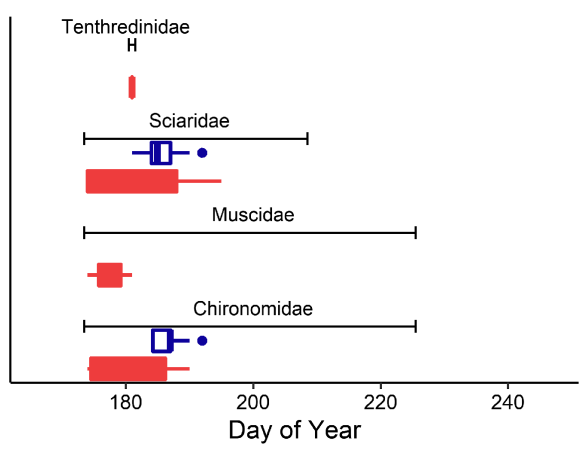

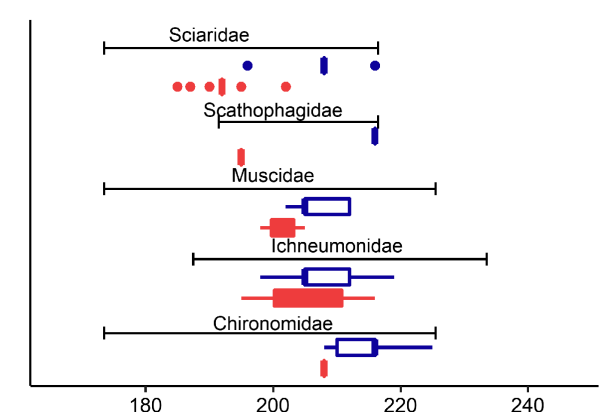

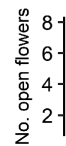

Cerastium arcticum
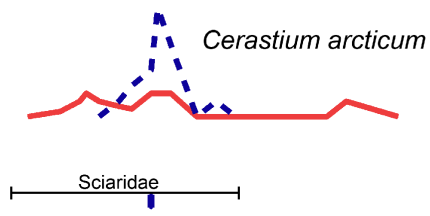

Spathophagidae

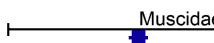

Ichneumonidae

Empididae

$\rightarrow$

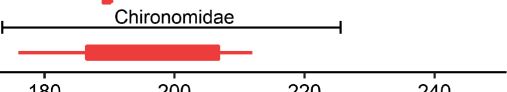

180

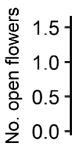

Stellaria longipes

subsp. longipes
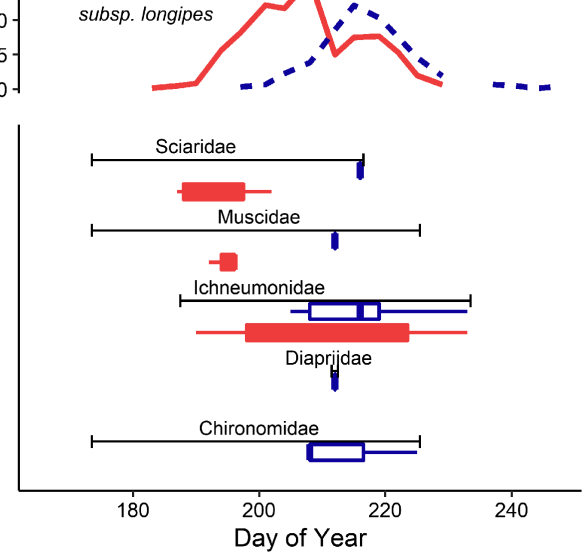

- Published by Canadian Science Publishing 
but tend to focus visits during the middle of the flowering phenophase in many cases. The data were insufficient for statistical detection of any phenological mismatches, but interestingly many insect families appeared to follow a sequence of preferred flowering species. The diagrams in Fig. 6 also demonstrate that some interactions were missing from Deep: Salix polaris with Musicade, Cassiope tetragona with Chironomidae, and Cerastium arctictim with Chironomidae and Empidae. It is not known whether these are particularly important interactions for either species and could also be an artefact of sampling error. There were also links missing from Ambient: Cerastium arcticum with Sciaridae and Scathophagidae, and Stellaria longipes subsp. longipes with Chironomidae.

\section{Discussion}

\section{Static Svalbard network}

When viewed at a comparable taxonomic level, the Adventdalen network is similar to other Arctic networks in terms of the low number of vascular plants and, as expected, has the lowest number of insect families involved. The complexity of the Adventdalen network in terms of number of interactions is most similar to that found on the Greenlandic island of Uummannaq (Lundgren and Olesen 2005). While our family level connectance estimate was higher than at Uummannaq indicating more generalist members of the network, plant generalisation was at a similarly low level. These properties can be explained partly by the low level of biodiversity of High Arctic regions generally (Callaghan et al. 2004), and by the geographic patterns of network properties (Olesen and Jordano 2002). While plant generalisation tends to increase with latitude and at lowland sites, specialisation tends to increase on islands due to low pollinator diversity. As insect-species-poor islands at high latitudes, Svalbard, Uummannaq, and indeed Ellesmere Island appear to represent a tradeoff of these general patterns: the trend towards plant generalisation is mediated by the low pollinator diversity of Arctic island ecosystems. The Adventdalen network is also entirely made up of species from the Diptera and parasitoid Hymenoptera, unlike networks further south and elsewhere in the Arctic that have at least a few species of bee, moth and (or) butterfly performing a pollination role. This is not surprising given the dominance of these orders in the Svalbard insect fauna (Dipera: 62\% of insect species, Hymenoptera: 13\%; Gillespie et al. 2020), and supports previous observations of dipteran dominance of pollination at high latitudes (Elberling and Olesen 1999; Lundgren and Olesen 2005; Rasmussen et al. 2013; Robinson et al. 2018). Of the Diptera order, the Muscidae family is a particularly important group of pollinators in Arctic and alpine systems (Pont 1993; Elberling and Olesen 1999; Tiusanen et al. 2016), especially the genus Spilogona. In Svalbard, this is the only genus of muscid flies known to occur (Gillespie et al. 2020), and they are likely to be important pollinators because of their large body size and elongated proboscis providing access to closed flowers (Pont 1993).

As with many other plant-visitor networks, the Adventdalen network displays a pattern of generalist plant and insect-visitor species and a number of less common species that are attached to the network with a low number of interactions (Bascompte and Jordano 2007). Generalists tend to occur in higher abundances with low population fluctuations relative to rarer species (Rasmussen et al. 2013). The most common plant species are likely to be more apparent and attractive to insect visitors and other consumers (Cooper and Wookey 2003; Gillespie et al. 2016). We lack the data to determine whether the rarer species here are specialists, but true specialists are not common to Arctic networks (Olesen and Jordano 2002), because high-latitude communities tend to be subject to severe abiotic conditions and limiting resources and species exhibit wider niches, as also shown for high-altitude networks (Hoiss et al. 2015). Studies of networks at high elevations have also shown that plants and pollinators are more generalist in terms of interacting partners than 
those at low elevations (Ramos-jiliberto et al. 2010; Hoiss et al. 2015), resulting in networks with less specialisation and structure. High generalisation among insect visitors is, therefore, likely to be an important compensatory feature for such species-poor networks as those reported here. Nevertheless, species-poor pollinator networks occurring in highly seasonal systems are also subject to low stability and resilience in the face of perturbations such as sudden climatic changes (Encinas-Viso et al. 2012).

\section{Dynamic network}

The dynamic aspects of the network displayed similar characteristics to those of previous studies with strong temporal dynamics in species number and linkage level (Pradal et al. 2009). In particular, the network shows rapid growth during the middle of the season in July, coinciding with peak flower production and insect visitation at our site (Gillespie et al. 2016), and insect emergence in Arctic regions generally (Olesen et al. 2008; Robinson et al. 2018), followed by a period of stasis where few new attachments are made in a system that is undergoing senescence and low foraging levels (Olesen et al. 2008). However, there are indications that this network does not exhibit the drastic collapse at the end of summer found in Greenlandic networks (Pradal et al. 2009). The Adventdalen network shows a similar pattern to the High Arctic network from Ellesmere Island described by Robinson et al. (2018). Both networks exhibit a slow build-up of complexity as new species enter the network, and a less dramatic "collapse" following peak community flower expansion. This may be an artefact of the taxonomic level of identification or a lack of survey days in both studies, but may also be indicative of a species-poor network operating under harsh weather conditions and low discrimination by insects in interaction partnerships. This is supported by the finding that, in the Adventdalen network, the main flower-visiting insect families have active adult phenophases that are relatively well spread out over the season, suggesting a slow decrease in turnover towards the end of the season, and a maximizing of phenological coupling between available mutualists (Encinas-Viso et al. 2012). These species may be adaptable to future changing plant phenologies, provided they are able to emerge from winter hibernation to coincide with flowering.

\section{Response of networks to snow regimes}

Our experimental data from the snow fences come with a caution. Generally, networks collected from replicated plots tend to be small and potentially biased in that they do not sample all the interactions present (Jordano 2016). Similarly, the areas affected by the snow fence are relatively small compared with the total study area (Kenkel and Podani 1991), and the majority of insects are likely to have emerged elsewhere. Therefore, the results of this study should be viewed from the perspective of the manipulation of the flowering phenology only (i.e., only one half of the interaction).

We found little difference in the structure of the static networks between Deep and Ambient (data not shown), but the temporal build-up of species and links involved in the network differed between regimes with a mean delay of 8-12 days, and this difference appeared to be relatively conserved across the season. While our Deep regime did not lead to a quantifiable temporal mismatch or a disruption in the interactions between insects and plants, delayed melting did shift the peak growth of the network and shortened the flowering season for these plots. This suggests that the two networks show the same gradual build-up and decline but implies a more dramatic collapse with delayed snow melt, delayed flowering, and reduced flowering duration. This supports the point made by Pradal et al. (2009) that the collapse of the Arctic plant-visitor network may be due to a sudden absence of flowering plants. 
Our prediction (H3) that delayed flowering would result in reduced availability of resources was confirmed by our findings, but it did not lead to temporal phenological mismatches. The path model suggests that there is potential for phenological mismatch between flowering plants and flower-visiting insects with enhanced snow, as short phenological overlap between species pairs is a key reason for unobserved or "forbidden" links in a network (Olesen et al. 2011). In the Deep, a reduction in phenophase overlap reflects fewer resources for insect visitors with consequences for the probability of visitation, and presumably pollination. This may be a contributing factor to the reduced cover of some species in the Deep regime since the snow fence experiment began (Semenchuk et al. 2013; Cooper et al. 2019). If the vegetation in Deep represents future Arctic conditions (for example, in the event of increased winter snowfall; Saha et al. 2006), this could have important ramifications for both plants and insects. Shorter flower seasons and declining insect visitor abundance have been linked to climate change elsewhere in the Arctic (Høye et al. 2013). Furthermore, the impact of snow depth on overlap and visitation may be an underestimate because we only manipulated one trophic level. By the time the Deep plots were in flower, the availability of abundant insect visitors had become established from feeding on flowers in Ambient and the surrounding landscape. If delayed snow melt was to occur over a wider homogenous area, the insects would be likely to delay their emergence at a similar rate to the flowers. This would both shorten the flowering season and reduce the amount of time available for insects to build-up the network and generate the periods of phenophase overlap required to ensure a high probability of interaction. Conversely, our experimental design is likely to represent a scenario of patchy distribution of deep and shallow snow depths across the landscape, leading to heterogeneity in the timing of flower availability. This may have the effect of extending the flowering season, and if insect-visitor emergence is unaffected, they are likely to benefit from an increased temporal availability of resources. However, this is a simplification of likely future changes, as soil and air temperature, frost, $\mathrm{CO}_{2}$, and vegetation change are also all likely to impact flower and insect emergence and abundance in snow-covered landscapes (Høye et al. 2013, 2021; Kudo and Cooper 2019).

Comparisons of dates of flowering and insect visitation between the two regimes also revealed interesting patterns, with common insects apparently spending short periods foraging from the most common plant species, suggesting that they tended to move between flowering species at their peak. The additional availability of flowers later in the season in Deep is also likely to have had an effect of prolonging the period of peak availability of flowers and density of the insect species. For example, ichnuemonid wasps and chironomids both appear to visit D. octopetala flowers in Deep after peak flowering in Ambient, even though some flowers of this species were still available in Ambient. This pattern of visitation can be explained by theories of optimal foraging (Macarthur and Pianka 1966), whereby the relative abundance of high-quality food resources determines the usefulness of lower quality food sources. As early flowering plants decrease in their density and quality they become less apparent and attractive, particularly given the emergence and peak density (and presumable quality) of other food sources (Cooper and Wookey 2003; Kudo and Cooper 2019). These changes in abundance can be important factors in interaction assembly and disassembly in networks (Caradonna et al. 2017), and plant switching in response to changing abundances has been found in other food webs (Carnicer et al. 2009).

The visitation patterns of insect families may also be indicative of the neutrality hypothesis of mutualistic networks, whereby relative species abundances predict interaction frequencies (Vázquez and Aizen 2004), rather than species traits or phenology. If this is the case, changing flower phenology will perhaps have lower impact on network properties in such a general, species-poor network, as most of the insects are flexible in their food 
sources. The alternative, the biological constraints hypothesis, suggests that forbidden links determine network structure (Bascompte and Jordano 2007; Olesen et al. 2011), where links between a plant and insect-visitor are not possible due to morphological or phenological incompatibility. In this case, changing plant phenology would lead to an increase in forbidden links locally, as seen in our Deep regime above. Our experiment did not allow the detection of any complete mismatches, rather a reduced probability of interaction at low levels of overlap. In any case, Vázquez et al. (2009) suggest that both relative abundances and spatiotemporal distribution of plants and insects are together important contributors of network structure and resilience.

In summary, our data suggest that in snow-covered landscapes such as High Arctic tundra, changes in the temporal and spatial snow melt conditions may benefit some flowering plants and insects by providing more opportunities to interact, and such flexibility in resource use could enhance the network's resilience to perturbations such as phenological changes (Burkle et al. 2013; Caradonna et al. 2017). However, this is likely to be dependent on the timing of insect emergence in changing conditions. For plants, a reduced probability of visitation in areas of deep snow and therefore late melt will likely impact patch occupancy, partly through limiting reproduction if snow melt change is variable spatially and temporally. If snow depth increases or snow melt is delayed more widely throughout the landscape, both trophic levels are likely to be negatively impacted by the shortening season (Høye et al. 2013). In general, the impact of climate change factors on the timing of peak densities of individual flower species, and the overlap of these peak densities, may be an important determinant of species interactions at the community level (Hegland et al. 2009; Rafferty et al. 2015). We suggest that further experimental and long-term observational research would help to confirm these findings and to assess the likelihood of these patterns predicting future effects for snow-covered landscapes at lower latitudes.

\section{Acknowledgements}

We thank Saskia Bergmann, Nanna Baggesen, and Yuko Kusama for help gathering data, and we thank Martin Lorig and the University Centre in Svalbard for logistical support. Steve Coulson is thanked for his invaluable advice, logistical support, and comments on a previous version of the manuscript. Stein Joar Hegland and Pete Convey are also thanked for their advice and input on the manuscript.

\section{Competing interests}

The authors declare there are no competing interests.

\section{Author contributions}

E.J.C. conceived and designed the snow fence experiment. M.A.K.G. collected and analysed the data. M.A.K.G. and E.J.C. wrote the manuscript.

\section{Funding statement}

This work was funded by the Norwegian Research Council via the SnoEco project (number 230970, to E.J.C.) and an Arctic Field Grant (number 246093/E10 to M.A.K.G.) and a Terrestrial Flagship grant (project SnoEcoPhen) to E.J.C.

\section{References}

Alsos, I.G., Arnesen, G., Elven, R., and Sandbakk, B.E. 2020. The flora of Svalbard. Available from https:// svalbardflora.no/oldsite/ [accessed 16 February 2021].

Bascompte, J., and Jordano, P. 2007. Plant-animal mutualistic networks: the architecture of biodiversity. Annu. Rev. Ecol. Evol. Syst. 38: 567-593. doi: 10.1146/annurev.ecolsys.38.091206.095818.

Bascompte, J., and Jordano, P. 2014. Mutualistic networks. Princeton University Press. 
Bascompte, J., Jordano, P., Melian, C.J., and Olesen, J.M. 2003. The nested assembly of plant-animal mutualistic networks. Proc. Natl. Acad. Sci. USA, 100: 9383-9387. doi: 10.1073/pnas.1633576100. PMID: 12881488.

Bay, C. 2020. Four decades of new vascular plant records for Greenland. PhytoKeys, 145: 63-92. doi: 10.3897/ phytokeys.145.39704. PMID: 32327927.

Brooks, M.E., Kristensen, K., Van Benthem, K.J., Magnusson, A., Berg, C.W., Nielsen, A., et al. 2017. glmmTMB balances speed and flexibility among packages for zero-inflated generalized linear mixed modeling. R J. 9: 378-400. doi: 10.32614/RJ-2017-066.

Burkle, L.A., and Alarcón, R. 2011. The future of plant-pollinator diversity: understanding interaction networks across time, space, and global change. Am. J. Bot. 98: 528-538. doi: 10.3732/ajb.1000391. PMID: 21613144.

Burkle, L.A., Marlin, J.C., and Knight, T.M. 2013. Plant-pollinator interactions over 120 years: loss of species, co-occurrence, and function. Science, 339: 1611-1615. doi: 10.1126/science.1232728. PMID: 23449999.

Callaghan, T.V., Bjorn, L.O., Chernov, Y., Chapin, T., Christensen, T.R., Huntley, B., et al. 2004. Biodiversity, distributions and adaptations of Arctic species in the context of environmental change. Ambio, 33: 404-417. doi: 10.1579/ 0044-7447-33.7.404. PMID: 15573569.

Caradonna, P.J., Petry, W.K., Brennan, R.M., Cunningham, J.L., Bronstein, J.L., Waser, N.M., and Sanders, N.J. 2017. Interaction rewiring and the rapid turnover of plant-pollinator networks. Ecol. Lett. 20: 385-394. doi: 10.1111/ ele.12740. PMID: 28156041.

Carnicer, J., Jordano, P., and Melián, C.J. 2009. The temporal dynamics of resource use by frugivorous birds: a network approach. Ecology, 90: 1958-1970. doi: 10.1890/07-1939.1. PMID: 19694143.

Cooper, E.J., and Wookey, P.A. 2003. Floral herbivory of Dryas octopetala by Svalbard reindeer. Arct. Antarct. Alp. Res. 35: 369-376. doi: 10.1657/1523-0430(2003)035[0369:FHODOB]2.0.CO;2.

Cooper, E.J., Dullinger, S., and Semenchuk, P. 2011. Late snowmelt delays plant development and results in lower reproductive success in the High Arctic. Plant Sci. 180: 157-167. doi: 10.1016/j.plantsci.2010.09.005. PMID: 21421357.

Cooper, E.J., Little, C.J., Pilsbacher, A.K., and Mörsdorf, M.A. 2019. Disappearing green: shrubs decline and bryophytes increase with nine years of increased snow accumulation in the High Arctic. J. Veg. Sci. 30: 857-867. doi: 10.1111/jvs.12793.

Dormann, C.F., Gruber, B., and Fründ, J. 2008. Introducing the bipartite package: analysing ecological networks. R News, 8: 8-11.

Elberling, H., and Olesen, J.M. 1999. The structure of a high latitude plant-flower visitor system: the dominance of flies. Ecography, 22: 314-323. doi: 10.1111/j.1600-0587.1999.tb00507.x.

Encinas-Viso, F., Revilla, T.A., and Etienne, R.S. 2012. Phenology drives mutualistic network structure and diversity. Ecol. Lett. 15: 198-208. doi: 10.1111/j.1461-0248.2011.01726.x. PMID: 22236277.

Gillespie, L.J., Saarela, J.M., Sokoloff, P.C., and Bull, R.D. 2015. New vascular plant records for the Canadian Arctic Archipelago. PhytoKeys, 52: 23-79. doi: 10.3897/phytokeys.52.8721.

Gillespie, M.A.K., Baggesen, N., and Cooper, E.J. 2016. High Arctic flowering phenology and plant-pollinator interactions in response to delayed snow melt and simulated warming. Environ. Res. Lett. 11: 115006. doi: 10.1088/ 1748-9326/11/11/115006.

Gillespie, M.A.K., Alfredsson, M., Barrio, I.C., Bowden, J.J., Convey, P., Culler, L.E., et al. 2020. Status and trends of terrestrial arthropod abundance and diversity in the north Atlantic region of the Arctic. Ambio, 49: 718-731. doi: 10.1007/s13280-019-01162-5. PMID: 30879270.

Hartig, F. 2020. DHARMa: residual diagnostics for hierarchical (multi-level/mixed) regression models. R package version 0.3.3.0.

Hegland, S.J., Nielsen, A., Lazaro, A., Bjerknes, A.-L., and Totland, O. 2009. How does climate warming affect plant-pollinator interactions? Ecol. Lett. 12: 184-195. doi: 10.1111/j.1461-0248.2008.01269.x. PMID: 19049509.

Hoiss, B., Krauss, J., and Steffan-Dewenter, I. 2015. Interactive effects of elevation, species richness and extreme climatic events on plant-pollinator networks. Global Change Biol. 21: 4086-4097. doi: 10.1111/gcb.12968. PMID: 26332102.

Høye, T.T., and Forchhammer, M.C. 2008. Phenology of High-Arctic arthropods: effects of climate on spatial, seasonal, and inter-annual variation. Adv. Ecol. Res. 40: 299-324. doi: 10.1016/s0065-2504(07)00013-x.

Høye, T.T., Post, E., Schmidt, N.M., Trojelsgaard, K., and Forchhammer, M.C. 2013. Shorter flowering seasons and declining abundance of flower visitors in a warmer Arctic. Nat. Clim. Change, 3: 759-763. doi: 10.1038/ nclimate1909.

Høye, T.T., Loboda, S., Koltz, A.M., Gillespie, M.A.K., Bowden, J.J., and Schmidt, N.M. 2021. Nonlinear trends in abundance and diversity and complex responses to climate change in Arctic arthropods. Proc. Natl. Acad. Sci. USA, 118: e2002557117. doi: 10.1073/pnas.2002557117. PMID: 33431570.

Jordano, P. 2016. Sampling networks of ecological interactions. Funct. Ecol. 30: 1883-1893. doi: 10.1111/13652435.12763.

Kenkel, N.C., and Podani, J. 1991. Plot size and estimation efficiency in plant community studies. J. Veg. Sci. 2: 539-544. doi: 10.2307/3236036.

Kudo, G., and Cooper, E.J. 2019. When spring ephemerals fail to meet pollinators: mechanism of phenological mismatch and its impact on plant reproduction. Proc. R. Soc. B: Biol. Sci. 286: 20190573. doi: 10.1098/rspb.2019.0573.

Lefcheck, J.S. 2016. PIECEWISESEM: piecewise structural equation modelling in R for ecology, evolution, and systematics. Methods Ecol. Evol. 7: 573-579. doi: 10.1111/2041-210X.12512.

Lundgren, R., and Olesen, J.M. 2005. The dense and highly connected world of Greenland's plants and their pollinators. Arct. Antarct. Alp. Res. 37: 514-520. doi: 10.1657/1523-0430(2005)037[0514:TDAHCW]2.0.CO;2. 
Macarthur, R.H., and Pianka, E.R. 1966. On optimal use of a patchy environment. Am. Nat. 100: 603-609. doi: $10.1086 / 282454$.

Memmott, J., Craze, P.G., Waser, N.M., and Price, M.V. 2007. Global warming and the disruption of plant-pollinator interactions. Ecol. Lett. 10: 710-717. doi: 10.1111/j.1461-0248.2007.01061.x. PMID: 17594426.

Morgner, E., Elberling, B., Strebel, D., and Cooper, E.J. 2010. The importance of winter in annual ecosystem respiration in the High Arctic: effects of snow depth in two vegetation types. Polar Res. 29: 58-74. doi: 10.1111/j.17518369.2010.00151.x.

Moriana-Armendariz, M., Nilsen, L., and Cooper, E.J. In press. Natural variation in snow depth and snow melt timing in the High Arctic have implications for soil and plant nutrient status and vegetation composition. Arct. Sci. doi: $10.1139 /$ as-2020-0025.

Nielsen, A., and Bascompte, J. 2007. Ecological networks, nestedness and sampling effort. J. Ecol. 95: 1134-1141. doi: 10.1111/j.1365-2745.2007.01271.x.

Olesen, J.M., and Jordano, P. 2002. Geographic patterns in plant-pollinator mutualistic networks. Ecology, 83: 2416-2424. doi: 10.2307/3071803.

Olesen, J.M., Bascompte, J., Elberling, H., and Jordano, P. 2008. Temporal dynamics in a pollination network. Ecology, 89: 1573-1582. doi: 10.1890/07-0451.1. PMID: 18589522.

Olesen, J.M., Bascompte, J., Dupont, Y.L., Elberling, H., Rasmussen, C., and Jordano, P. 2011. Missing and forbidden links in mutualistic networks. Proc. R. Soc. B: Biol. Sci. 278: 725-732. doi: 10.1098/rspb.2010.1371.

Petanidou, T., Kallimanis, A.S., Tzanopoulos, J., Sgardelis, S.P., and Pantis, J.D. 2008. Long-term observation of a pollination network: fluctuation in species and interactions, relative invariance of network structure and implications for estimates of specialization. Ecol. Lett. 11: 564-575. doi: 10.1111/j.1461-0248.2008.01170.x. PMID: 18363716.

Poisot, T., Stouffer, D.B., and Gravel, D. 2015. Beyond species: why ecological interaction networks vary through space and time. Oikos, 124: 243-251. doi: 10.1111/oik.01719.

Pont, A. 1993. Observations on anthophilous Muscidae and other Diptera (Insecta) in Abisko National Park, Sweden. J. Nat. Hist. 27: 631-643. doi: 10.1080/00222939300770361.

Pradal, C., Olesen, J.M., and Wiuf, C. 2009. Temporal development and collapse of an Arctic plant-pollinator network. BMC Ecol. 9: 24. doi: 10.1186/1472-6785-9-24. PMID: 19961607.

R Core Team. 2019. R: a language and environment for statistical computing. 3.6.2 ed. R Foundation for Statistical Computing, Vienna, Austria.

Rafferty, N.E., Caradonna, P.J., and Bronstein, J.L. 2015. Phenological shifts and the fate of mutualisms. Oikos, 124: 14-21. doi: 10.1111/oik.01523. PMID: 25883391.

Ramos-Jiliberto, R., Domínguez, D., Espinoza, C., López, G., Valdovinos, F.S., Bustamante, R.O., and Medel, R. 2010. Topological change of Andean plant-pollinator networks along an altitudinal gradient. Ecol. Complexity, 7: 86-90. doi: 10.1016/j.ecocom.2009.06.001.

Rasmussen, C., Dupont, Y.L., Mosbacher, J.B., Trøjelsgaard, K., and Olesen, J.M. 2013. Strong impact of temporal resolution on the structure of an ecological network. PLoS ONE, 8: e81694. doi: 10.1371/journal.pone.0081694. PMID: 24324718.

Robinson, S.V.J., Losapio, G., and Henry, G.H.R. 2018. Flower-power: flower diversity is a stronger predictor of network structure than insect diversity in an Arctic plant-pollinator network. Ecol. Complexity, 36: 1-6. doi: 10.1016/j.ecocom.2018.04.005.

Saha, S.K., Rinke, A., and Dethloff, K. 2006. Future winter extreme temperature and precipitation events in the Arctic. Geophys. Res. Lett. 33: L15818. doi: 10.1029/2006GL026451.

Schmidt, N.M., Mosbacher, J.B., Nielsen, P.S., Rasmussen, C., Hoye, T.T., and Roslin, T. 2016. An ecological function in crisis? The temporal overlap between plant flowering and pollinator function shrinks as the Arctic warms. Ecography, 39: 1250-1252. doi: 10.1111/ecog.02261.

Semenchuk, P.R., Elberling, B., and Cooper, E.J. 2013. Snow cover and extreme winter warming events control flower abundance of some, but not all species in High Arctic Svalbard. Ecol. Evol. 3: 2586-2599. doi: 10.1002/ ece3.648. PMID: 24567826.

Semenchuk, P.R., Gillespie, M.A.K., Rumpf, S.B., Baggesen, N., Elberling, B., and Cooper, E.J. 2016. High Arctic plant phenology is determined by snowmelt patterns but duration of phenological periods is fixed: an example of periodicity. Environ. Res. Lett. 11: 125006. doi: 10.1088/1748-9326/11/12/125006.

Shipley, B. 2000. A new inferential test for path models based on directed acyclic graphs. Struct. Equ. Model. 7: 206-218. doi: 10.1207/S15328007SEM0702_4.

Tiusanen, M., Hebert, P.D.N., Schmidt, N.M., and Roslin, T. 2016. One fly to rule them all-muscid flies are the key pollinators in the Arctic. Proc. R. Soc. B: Biol. Sci. 283: 20161271. doi: 10.1098/rspb.2016.1271.

Valverde, J., Gomez, J.M., and Perfectti, F. 2016. The temporal dimension in individual-based plant pollination networks. Oikos, 125: 468-479. doi: 10.1111/oik.02661.

Vázquez, D.P., and Aizen, M.A. 2004. Asymmetric specialization: a pervasive feature of plant-pollinator interactions. Ecology, 85: 1251-1257. doi: 10.1890/03-3112.

Vázquez, D.P., Bluthgen, N., Cagnolo, L., and Chacoff, N.P. 2009. Uniting pattern and process in plant-animal mutualistic networks: a review. Ann. Bot. 103: 1445-1457. doi: 10.1093/aob/mcp057. PMID: 19304996.

Wood, S.N. 2017. Generalized additive models: an introduction with R. CRC Press. 